\title{
The relationship between nutrition reading and label use and nutrition knowledge amongst a sample of rural youth studying at a university in South Africa
}

\begin{tabular}{|c|c|}
\hline \multicolumn{2}{|c|}{$\begin{array}{l}\text { Authors: } \\
\text { Nomasonto Xazela }^{1} \text { (D) } \\
\text { Willie T. Chinyamurindi } \\
\text { Herring Shava }{ }^{2} \text { (I) }\end{array}$} \\
\hline \multicolumn{2}{|c|}{$\begin{array}{l}\text { Affiliations: } \\
{ }^{1} \text { Department of Livestock and } \\
\text { Pasture Science, University of } \\
\text { Fort Hare, Alice, South Africa }\end{array}$} \\
\hline \multicolumn{2}{|c|}{$\begin{array}{l}{ }^{2} \text { Department of Business } \\
\text { Management, University of } \\
\text { Fort Hare, Alice, South Africa }\end{array}$} \\
\hline \multicolumn{2}{|c|}{$\begin{array}{l}\text { Corresponding author: } \\
\text { Willie Chinyamurindi, } \\
\text { wchinyamurindi@ufh.ac.za }\end{array}$} \\
\hline \multicolumn{2}{|c|}{$\begin{array}{l}\text { Dates: } \\
\text { Received: } 04 \text { Apr. } 2019 \\
\text { Accepted: } 02 \text { Sept. } 2019 \\
\text { Published: } 12 \text { Nov. } 2019\end{array}$} \\
\hline \multicolumn{2}{|c|}{$\begin{array}{l}\text { How to cite this article: } \\
\text { Xazela, N., Chinyamurindi, } \\
\text { W.T. \& Shava, H., 2019, 'The } \\
\text { relationship between } \\
\text { nutrition reading and label } \\
\text { use and nutrition knowledge } \\
\text { amongst a sample of rural } \\
\text { youth studying at a universit } \\
\text { in South Africa', Health SA } \\
\text { Gesondheid } 24(0), \text { a1320. } \\
\text { https://doi.org/10.4102/ } \\
\text { hsag.v24i0.1320 }\end{array}$} \\
\hline \multicolumn{2}{|c|}{$\begin{array}{l}\text { Copyright: } \\
\text { (C) 2019. The Authors. } \\
\text { Licensee: AOSIS. This w } \\
\text { is licensed under the } \\
\text { Creative Commons } \\
\text { Attribution License. }\end{array}$} \\
\hline \multicolumn{2}{|l|}{ Read online: } \\
\hline 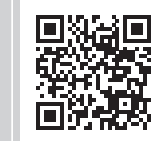 & $\begin{array}{l}\text { Scan this QR } \\
\text { code with your } \\
\text { smart phone or } \\
\text { mobile device } \\
\text { to read online. }\end{array}$ \\
\hline
\end{tabular}

Background: Within rural communities, quests for understanding consumer behaviour patterns become key, especially given the challenges that exist in such communities. Furthermore, youth consumers are an important cohort in rural communities in South Africa. Yet little empirical work has been conducted in studying their consumptive habits (usually in favour of youths in urban areas).

Aim: This study sought to measure the relationship between nutrition label use and nutrition knowledge amongst a sample of rural youth. This also included ascertaining the roles of demographic variables such as (1) gender and (2) and the number of years in tertiary education in this relationship.

Setting: The study was located within a South African rural context using a sample of rural youths.

Method: A quantitative study was utilised by means of a self-administered questionnaire, involving 150 youths residing in a rural community located in the Eastern Cape province of South Africa. Inferential statistical analysis was conducted using correlation tests, analysis of variance and linear regression.

Results: Three main findings emerged. Firstly, rural youth consumers' nutrition label use had no significant relationship with nutrition knowledge. Secondly, no significant difference existed by gender concerning nutrition knowledge. Finally, the level of education amongst the rural youth consumers had no relationship with aspects of nutrition knowledge.

Conclusion: Based on the findings, recommendations are made not only for theory and practice but also for policy in relation to both the rural context and for optimal health.

Keywords: rural; youth; consumer nutrition label use; nutrition knowledge; nutrition reading.

\section{Introduction}

Nutrition knowledge and understanding the importance thereof is regarded as a major means of encouraging consumers in making healthier choices (Deshmukh \& Goyal 2017). Key to this understanding is the interaction that exists between individuals and their environment (Grunert et al. 2010). Quests in understanding how to improve nutrition knowledge acquisition can be a useful basis not only for community interventions to challenges such as obesity, but also to ensure a sustainable livelihood (Flynn 2015). In the extant literature, calls exist for more research exploring how aspects of individual and societal behaviour relate to nutrition knowledge (Kabir, Miah \& Islam 2018).

Furthermore, the role of nutrition label use in nutrition knowledge, despite being an underexplored focus area in rural communities, can be a worthwhile investigation based on three reasons. Firstly, rural communities are overburdened with challenges such as poverty (Van Schalkwyk 2015). Thus, poverty exists as a potential deterrent to consumptive habits. This presents a need to seek ways of curtailing such limitations. Secondly, because of the aspect of poverty, rural inhabitants are limited in terms of food consumption. This is compounded by a lack of knowledge concerning the difference between healthy and unhealthy food (Hendriks \& McIntyre 2016). Finally, a general observation in South African rural communities is the role that biographical factors can play, not only in the acquisition of knowledge concerning nutrition 
but also regarding responses to nutrition interventions (Kimani-Murage et al. 2010).

\section{Problem statement}

Young people in South Africa currently face a myriad of challenges, predominantly unemployment (Coetzee 2014). Furthermore, South Africa, like the rest of the African continent, is argued to have a young yet also growing population (Page 2012). One key risk that youths face has to do with aspects of the choices made concerning their health (Amy 2019). A call exists (World Health Organization 2014) to prioritise understanding around the challenges concerning aspects of health of the youth. The ramification here is that youths are the future leaders of economies and hence the focus to help them charter and occupy this position through better healthcare.

Issues that could be of interest here are to understand the networks youths use to access information about health (Hampshire et al. 2015). Narrowly, the interest here is on understanding issues concerning nutrition knowledge and how it relates to the youth market. Therefore, the purpose of this study was to identify and prioritise issues about nutrition label use, nutrition knowledge and, based on the findings, to propose ways in which rural inhabitants can live not only sustainably but also with a development focus in mind. This can be a useful precursor to interventions that find solutions to nutrition-related challenges evident in rural communities.

\section{Literature review}

\section{Nutrition knowledge}

Nutrition knowledge has been reported to mediate the relationship between socio-economic status and diet quality (Psaltopoulou et al. 2017). Regular and adequate supply of a variety of foods can be ensured through financial security, the lack of which leads to lower levels of malnutrition (underand over-nutrition). In addition, the risk of developing chronic diseases because of poor lifestyle will be mitigated (Pretorius \& Sliwa 2011).

The availability of and access to nutritious, diverse and balanced diets were identified as key constraints in achieving food and nutrition security and overall to human health and well-being (Govender et al. 2017). Calls have been made for a more expansive understanding of issues of nutrition knowledge and how this relates to aspects such as decisionmaking and human behaviour (Miller \& Cassady 2015).

\section{Influence of demographics on nutrition knowledge}

Food cost is noted as a contributor towards socio-economic patterning and choices of a healthy diet. Higher occupational social class is significantly associated with greater food expenditure, which in turn is associated with healthier purchasing (Pechey \& Monsivais 2016). With respect to gender and education levels, it has been established that generally women and people with higher education levels have good nutrition knowledge (Laz et al. 2015).

Concerning age, a positive link appears to exist between the level of nutrition knowledge (Romanos-Nanclares et al. 2018) and age, with adult consumers having a better understanding of nutrition knowledge than young people. Furthermore, studies have shown that maternal access to nutrition is important during childhood years and later age (Jones et al. 2014). The thinking here is that access to good nutritious food in childhood sets the individual for a healthy life, both during adolescence (Govender et al. 2018) and later in adult life (Grosso et al. 2012). Based on all the presented literature, the following hypotheses were set:

Hypothesis 1: Women have higher nutrition knowledge scores compared to men.

Hypothesis 2: The number of years of tertiary education has a significant effect on the nutrition knowledge of the youth.

\section{Nutrition label use and nutrition knowledge}

As consumers have become gradually selective about what they consume and how it affects their health, the food industry has responded by providing more detailed nutrition information on food labels (Petrovici et al. 2012). In 2010, South Africa and other African countries took bold steps to enact a law for publishing food contents on labels (Kempen et al. 2012). Despite these legislative efforts, consumers continue to struggle in making decisions concerning food choices (Miller et al. 2017). These challenges may be the cause of individual knowledge processing and not necessarily of the use of nutrition labels. Therefore, it is hypothesised that:

Hypothesis 3: Nutrition label use is positively related to nutrition knowledge.

\section{Reading of nutrition information and nutrition knowledge}

Reading the nutrition information may assist an individual in making healthier food choices (Azman \& Sahak 2014). Some consumers experience challenges when reading nutrition labels, such as the font size of nutrition information being too small and understanding terminology used in the ingredients list (Koen et al. 2016). However, Van der Merwe et al. (2013) reported that South African consumers selectively read nutrition information on food labels. Some consumers added that they were unsure of their understanding of the information provided (Kempen et al. 2012). Not reading the nutrition label may be because some consumers do not understand all the information or they are unwilling to read or to invest time in understanding it (Guthrie, Mancino \& Lin 2015). The challenges may be in understanding the numerical information and differences in amount of fats or other nutrients when comparing products (Miller et al. 2015). Thus, the lack of reading of nutrition labels may be attributed to the lack of exposure and understanding (Matthews, Doerr \& Dworatzek 2015). The primary goal should be to provide clear guidance on 
how best to select food items for a healthy diet (Moore et al. 2018). Hence, this study hypothesised that:

Hypothesis 4: Reading of nutrition labels is significantly related to nutrition knowledge.

\section{Methodology}

The study followed a quantitative methodology utilising a self-administered questionnaire. The motivation behind quantitative research is to produce information and enable an understanding about the social world (Antwi \& Hamza 2015). It gives answers to questions regarding the recurrence of a phenomenon, or the extent to which the phenomenon affects the sample population. The advantage of a selfadministered questionnaire is that it allows users to collect a vast amount of data in a short period of time and economically (Picincu 2018).

\section{Sample and procedure}

Data were gathered through a self-administered questionnaire targeted at youth respondents residing in a rural area of the Eastern Cape province of South Africa. The justification for this is that a rural community under study faces significant challenges that relate to aspects of health and where nutrition plays an important role (Parliamentary Monitoring Group 2016). A non-probability convenience sampling approach was utilised because of the difficulty of accessing a reliable sample base. Furthermore, the researchers were impeded by challenges such as costs of conducting the research and hence the use of such a sampling approach and technique. The survey was conducted in September 2018, where the selection of participants was done randomly. The participants were approached and asked if they are interested about the study. When the consumer agreed to be part of the study, the enumerator explained the purpose of the study and the interviewer signed the consent form. These respondents were university students who were studying at a historically black institution, which is based in a rural area. The final number of respondents who participated in the study was 150, of which 65 were men and 85 were women.

\section{Instrument}

The survey instrument was composed of three sections. The first section consisted of demographic questions related to the respondents' gender, years of study at a tertiary institution, nationality and age. The second section of the questionnaire had questions related to food nutrition label use adapted from an international study (De Magistris, Gracia \& Barreiro-Hurle 2010). The items as guided by De Magistris et al. (2010) were split into three groups: (1) ingredients use, (2) nutrition facts and (3) nutrition claims. In testing the reliability, the nutrition label use scale had a Cronbach's alpha coefficient of 0.73, which is above the recommended threshold of 0.7 (Nunnally 1978). An example item of the nutrition label use scale was the following: 'as a consumer, I use nutrition labels when shopping' and this was measured using a four-point Likert scale, where 1 = never; 2 = once in a while; $3=$ often; and $4=$ always.
The final section of the questionnaire had questions concerning nutrition knowledge adapted from an international study (Krause et al. 2018) consisting of 12 items measured on a fourpoint Likert scale ( 1 = disagree strongly to $4=$ agree strongly). An example item is as follows: 'when I have questions on healthy nutrition, I know where I can find information on this issue'. In testing the reliability, the nutrition label use scale had a Cronbach's alpha coefficient of 0.73 , which is above the recommended threshold of 0.7 (Nunnally 1978). BarreirroHurle et al. (2010) validated these measures mentioned above through pilot surveys.

\section{Data analysis}

The Statistical Package for Social Sciences (SPSS) 2018 version 24 was used for data analysis (IBM 2016). Descriptive statistics were tested especially with the biographical data. Inferential statistics were tested through the independent samples $t$-test, the analysis of variance (ANOVA) and multiple linear regression. In other words, the study combined hypotheses 3 and 4 to determine if they predict nutrition knowledge. Initially, the hypotheses were formulated independently during the literature review with the goal of bringing to light the ongoing discussion about these variables.

\section{Ethical consideration}

Ethical approval for the study was obtained from the University of Fort Hare Research Ethics Committee (UREC) (ethical clearance number: $\mathrm{CHI021).}$

\section{Results}

The results of the study are presented and discussed in two sections. The first section focuses on the study's descriptive data. Table 1 provides a detailed description and means of variables used in the analysis of data. The data are presented with means for the two independent variables: nutrition labels and the nutrition knowledge. Years of study were excluded from the table although their combined mean was observed as 3.11 .

Table 2 lists the responses regarding the nutrition label use scale. Results in Table 2 concerning the question of food label awareness reveal that almost $61 \%$ of the youth are unaware of the contents on food labels. This could explain why $67 \%$ of the youth indicated that they read the nutrition information on the labels before placing food products into their shopping baskets. The $6 \%$ difference could be a result of using a dichotomous scale where 'yes/no' options were given. This accommodates those who may not be sure if they are fully aware of food labels and hence the $6 \%$ discrepancy. The thinking here is that the youth are eager to know the nutritional value of the food items before they consume. When asked how often they choose products with nutrition labels over products without labels, the majority of the respondents indicated that sometimes they do $(42 \%)$, with $22 \%$ indicating never and $23.3 \%$ indicating that nutrition labels do not influence their choices. Only 
TABLE 1: Description and means of the variables.

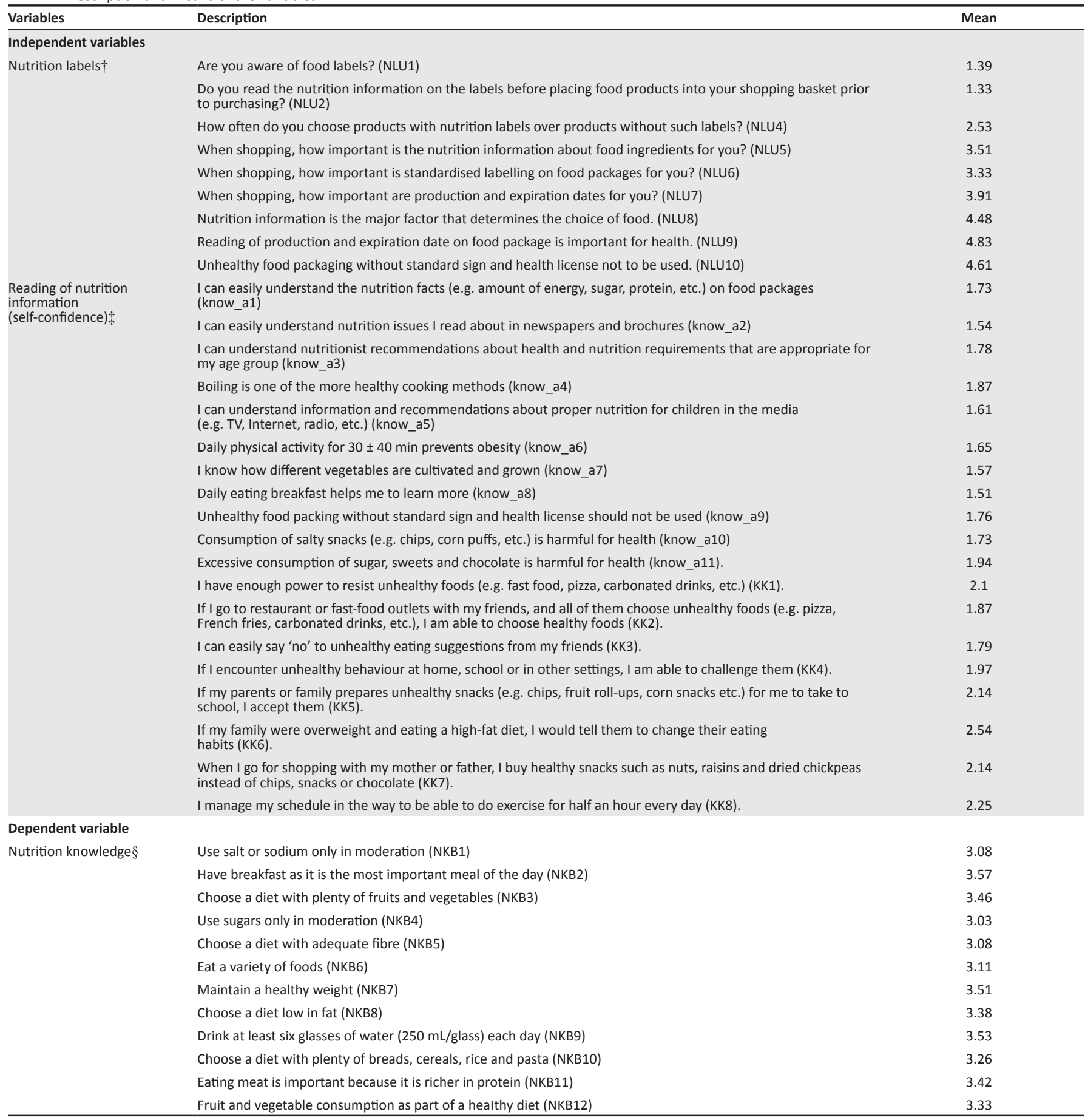

$\dagger$, NLU1 \& NLU2 measured as $1=$ yes and $2=$ no; NLU4 measured as $5=$ always, $4=$ often, $3=$ sometimes, $2=$ never and $1=$ nutrition label do not influence my choice; NLU5 to NLU7 measured as $4=$ very important, $3=$ somewhat important, $2=$ not too important and $1=$ not at all important; NLU 8 to NLU10 measured as $5=$ strongly agree, $4=$ agree, $3=$ neutral, $2=$ disagree and 1 = strongly disagree.

$\$$, Know_a1 to Know_a11 measured as No $=1$ and Yes $=2 ; \mathrm{KK} 1$ to $\mathrm{KK} 8$ measured as $3=$ always, $2=$ sometimes and $1=$ not at all.

$\S$, NKB1 to NKB12 measured as very important $=4$, somewhat important $=3$, not too important $=2$ and not at all important $=1$.

$9 \%$ of the respondents indicated that they choose products with nutrition labels over products without labels. When asked how important nutrition information about food ingredients is when doing shopping, $64 \%$ of the youth stated that it is very important and only $8.7 \%$ said it is not too important.

The results in Table 2 also indicate that $54.7 \%$ of the respondents consider standardised labelling on food packages as very important, with $21.3 \%$ of the respondents considering it as not too important. In addition, $91.3 \%$ of the respondents indicated that when doing their shopping, production and expiration dates of commodities are very important items and $8.7 \%$ indicated that they are somewhat important. It is further deduced from Table 2 that amongst the youth, nutrition information plays a critical role in determining the food items they buy $(62 \%$ of them strongly agreed, $23.3 \%$ agreed, $11.3 \%$ neither agreed nor disagreed 
TABLE 2: Distribution of responses (\%) to the label use questions.

\begin{tabular}{|c|c|c|c|c|c|c|c|c|c|}
\hline \multirow[t]{2}{*}{ Responses } & \multicolumn{9}{|c|}{ Question } \\
\hline & NLU1 & NLU2 & NLU4 & NLU5 & NLU6 & NLU7 & NLU8 & NLU9 & NLU10 \\
\hline Yes & 39.3 & 67.3 & - & - & - & - & - & - & - \\
\hline No & 60.7 & 32.7 & - & - & - & - & - & - & - \\
\hline Always & - & - & 9.3 & - & - & - & - & - & - \\
\hline Often & - & - & 3.3 & - & - & - & - & - & - \\
\hline Sometimes & - & - & 42 & - & - & - & - & - & - \\
\hline Never & - & - & 22 & - & - & - & - & - & - \\
\hline Nutrition labels do not influence my choice & - & - & 23.3 & - & - & - & - & - & - \\
\hline Very important & - & - & - & 64 & 54.7 & 91.3 & - & - & - \\
\hline Somewhat important & - & - & - & 25.3 & 24 & 8.7 & - & - & - \\
\hline Not too important & - & - & - & 8.7 & 21.3 & - & - & - & - \\
\hline Strongly agree & - & - & - & - & - & - & 62 & 83.3 & 72.7 \\
\hline Agree & - & - & - & - & - & - & 23.3 & 16.7 & 18 \\
\hline Neither agree nor disagree & - & - & - & - & - & - & 11.3 & - & 7.3 \\
\hline
\end{tabular}

NLU, Nutrition label use understanding.

and only $2 \%$ disagreed). In addition, it is evident that the majority of the youth consider reading the production and expiration dates on food packages as important for an individual's health, as represented by $83.3 \%$ of respondents who strongly agreed and an additional $16.7 \%$ who agreed. Finally, $72.7 \%$ of the youth also strongly agreed that unhealthy food packaging without a standard sign and health licence should not be used, $18 \%$ of the youth agreed, and only $7.3 \%$ neither agreed nor disagreed.

As mentioned earlier, the reading of the nutrition information scale was made up of two parts, with the first part comprising 11 questions measured on a dichotomous scale. From this information, a total score for each respondent could be computed. The minimum score would be $(1 \times 11=11)$ and the maximum score would be $(2 \times 11=22)$. From the observed scores in Table 1 , the total score for the youth is 18.68 , with a mean score of 1.7 . Although the value of 1.7 is close to 2 (on the mentioned dichotomous scale), the information indicates that the youth's score for reading nutrition information is above average. The second part of reading nutrition information had eight items measured on a three-point Likert scale. A total score was computed for this scale, with the minimum possible score established as $8(8 \times 1=8)$, the maximum possible score established as $24(8 \times 3=24)$ and the observed score as 16.8 , with a mean score of 2.1 . From the observed scores, it can be concluded that the youth scored far above the average score for reading of nutrition information.

Finally, the total score for the nutrition knowledge scale was computed with the goal of determining whether the youth had a high or low nutrition knowledge score. A similar approach in computing the total score was used. Thus, the minimum possible score of $12(12 \times 1=12)$ could be obtained given that the nutrition knowledge scale had 12 items measured on a four-point Likert scale, with 4 = very important and $1=$ not at all important. The maximum possible score would be $48(4 \times 12=48)$. Table 1 shows that a total of 39.76 , far above average, with a mean of 3.31 was scored. These results also indicate that the youth had a high score for
TABLE 3: Independent samples $t$-tests descriptive statistics and significance test output for gender.

\begin{tabular}{lccccc}
\hline $\begin{array}{l}\text { Nutrition } \\
\text { knowledge }\end{array}$ & Statistics & Sample size & Mean & SD & $\begin{array}{c}\text { Std. error } \\
\text { estimation }\end{array}$ \\
\hline Gender & - & 62 & 3.3454 & 0.28304 & 0.3595 \\
Male & - & 81 & 3.2942 & 0.30593 & 0.3399 \\
Female & 1.223 & - & - & - & - \\
Equal variances $(F)$ & 0.271 & - & - & - & - \\
Sig $(p)$ & 1.024 & - & - & - & - \\
$T$-value & 141.01 & - & - & - & - \\
$d f$ & 0.308 & - & - & - & - \\
$p$-value & &
\end{tabular}

SD, standard deviation; Std. error, standard error.

nutrition knowledge. Barreirro-Hurle et al. (2010) validated the measures mentioned above through pilot surveys.

The study's first hypothesis sought to investigate if there is a significant difference between men and women regarding nutrition knowledge. Table 3 reports on the results of this analysis. The independent samples $t$-test was undertaken and the mean score for men was 3.35, with a standard deviation (SD) of 0.28. The mean score for women was observed as 3.30, with an SD of 0.31. Equal variances were assumed, with $F=1.223$, Sig. $(p)=0.271$ giving the $t$-value $=$ 1.024 and degrees of freedom $=141.000$. From these figures, a $p$-value of 0.308 was obtained, indicating that the difference between means was not significant. In other words, amongst the youth in this study, the nutrition knowledge of men and women does not differ significantly.

The second hypothesis sought to determine whether the number of years of tertiary education has a significant effect on the nutrition knowledge of the youth. The thinking here is that as the youth complete more years at a tertiary institution, their nutrition knowledge should increase proportionately. In other words, those who have only completed a few years of tertiary education will most likely have less nutrition knowledge than those who have studied for longer. To investigate this hypothesis, a one-way independent ANOVA was undertaken. The ANOVA output (descriptive section) shows that first year students had a mean score of 3.43, SD of 0.193 and a standard error (SE) of 0.064 . The second year 
students had a mean score of 3.230, SD of 0.31 and SE of 0.07 . Finally, the third year students had a mean score of 3.330, SD of 0.260 and SE of 0.04 . To determine if these differences between the four groups were significant, the following figures were observed: $F(3.135)=1.347, p=0.262$. This is reported in Table $4 \mathrm{a}$ and Table $4 \mathrm{~b}$. (Based on the responses we received on the question regarding education level, the results indicated that $N=139$, meaning that out of the original $N=150$ students, 11 did not provide meaningful data on this question.)

The descriptive statistics and common knowledge point to the notion that as someone completes more years of education, the likelihood of having more nutrition knowledge

TABLE 4a: Analysis of variance descriptive statistics and significance test output for years of study.

\begin{tabular}{lccc}
\hline Year of Study & Sample Size & Std. Deviation & Std. Error \\
\hline 1st Year & 9 & 0.19295 & 0.06432 \\
2nd year & 19 & 0.31004 & 0.07113 \\
3rd year & 59 & 0.25622 & 0.03336 \\
4th year & 52 & 0.26453 & 0.03668 \\
\hline Total & $\mathbf{1 3 9}$ & $\mathbf{0 . 2 6 4 9 3}$ & $\mathbf{0 . 0 2 2 4 7}$ \\
\hline
\end{tabular}

Based on the responses we received on the question regarding education level, the results indicated that ( $N=139$, meaning that out of the original $N=150$ students, 11 did not provide meaningful data on this question)

TABLE 4b: Analysis of variance descriptive statistics and significance test output for years of study.

\begin{tabular}{lc}
\hline Statistics & Significance \\
\hline Levence statistic & 1.482 \\
df1 & 3 \\
df2 & 135 \\
sig & 0.222 \\
Sum of Squares between Groups & 0.282 \\
Sum of Squares within Groups & 9.405 \\
$F$ & 1.347 \\
Sig & 0.262 \\
\hline
\end{tabular}

Based on the responses we received on the question regarding education level, the results indicated that ( $N=139$, meaning that out of the original $N=150$ students, 11 did not provide meaningful data on this question)

TABLE 5: Multiple linear regression output: Pearson's correlation results regarding nutrition knowledge and label reading.

\begin{tabular}{lccc}
\hline Correlations & $\begin{array}{c}\text { Nutrition } \\
\text { Knowl_Belief }\end{array}$ & $\begin{array}{c}\text { Nutrition_ } \\
\text { LU5_7 }\end{array}$ & $\begin{array}{c}\text { Reading_of_ } \\
\text { NInfor }\end{array}$ \\
\hline Pearson correlation & 1.000 & 0.088 & 0.092 \\
Nutrition_Knowl_Belief & 0.088 & 1.000 & 0.154 \\
Nutrition_LU5_7 & 0.092 & 0.154 & 1.000 \\
Reading_of_NInfor & & & \\
Sig. (1-tailed) & - & 0.159 & 0.148 \\
Nutrition_Knowl_Belief & 0.159 & - & 0.040 \\
Nutrition_LU5_7 & 0.148 & 0.040 & - \\
Reading_of_NInfor & & & 131 \\
$\boldsymbol{N}$ & 131 & 131 & 131 \\
Nutrition_Knowl_Belief & 131 & 131 & 131 \\
Nutrition_LU5_7 & 131 & 131 & \\
Reading_of_NInfor & &
\end{tabular}

is greater for that person. However, the findings of the above ANOVA test indicated otherwise and there could be various reasons for this. One important possibility could be that the study respondents relied more on nutrition knowledge they had obtained during the adolescence stage and their tertiary education was not at all related to nutrition. Another reason could be that the respondents were majoring in disciplines not related to the health sciences. This could be that the campus in which the students were based did not offer health sciences-related courses.

To investigate whether nutrition label use and reading of nutrition information predict nutrition knowledge, a multiple linear regression was undertaken (see Tables 6-8). A positive but non-significant Pearson's correlation was observed between the predictor variables and the explanatory variable. Thus, a correlation of 0.088 was observed between nutrition label use and nutrition knowledge. This was observed through the regression analysis $(r=0.092)$ between reading of nutrition information and nutrition knowledge.

To determine if the explanatory variables had a unique contribution towards the model, results from the model summary table were examined and an $R$-square $=0.0140$ or $1.4 \%$ of the variance in nutrition knowledge is explained by reading of nutrition information and nutrition label use. Based on the data analysis, it can be observed that nutrition label use and reading of nutrition information do not predict nutrition knowledge as found amongst the participating respondents of the study.

Furthermore, the ANOVA results (from the multiple linear regression output) showed the results which explain whether the use of the model was significantly better at predicting nutrition knowledge of the youth. Given F (0.909) with a significance of 0.406 , the model was declared unfit. In other words, the model has no value in predicting youth nutrition knowledge. The $B$-values showed that a positive but nonsignificant relationship exists between nutrition label use and nutrition knowledge $(B=0.042 ; p=0.397)$. Also, a positive but non-significant relationship was confirmed between reading nutrition information and nutrition knowledge $(B=0.087 ; p=0.368)$.

TABLE 7: Multiple linear regression output - Analysis of variance results.

\begin{tabular}{lccccc}
\hline Model 1 & $\begin{array}{c}\text { Sum of } \\
\text { squares }\end{array}$ & df & Mean square & $\boldsymbol{F}$ & Sig. \\
\hline Regression & 0.118 & 2 & 0.059 & 0.909 & $0.406 \dagger$ \\
Residual & 8.275 & 128 & 0.065 & - & - \\
\hline Total & $\mathbf{8 . 3 9 2}$ & $\mathbf{1 3 0}$ & - & - & - \\
\hline
\end{tabular}

Note: ANOVA, Dependent Variable: Nutritionon_Knowl_Belief.

$\dagger$, Predictors: (Constant), Reading_of_NInfor, Nutrition_LU5_7

TABLE 6: Multiple linear regression output - Model summary results.

\begin{tabular}{|c|c|c|c|c|c|c|c|c|c|c|}
\hline \multirow[t]{2}{*}{ Model } & \multirow[t]{2}{*}{$R$} & \multirow[t]{2}{*}{$R$-square } & \multirow{2}{*}{$\begin{array}{l}\text { Adjusted } \\
R \text {-square }\end{array}$} & \multirow{2}{*}{$\begin{array}{l}\text { Std. error of } \\
\text { the estimate }\end{array}$} & \multirow{2}{*}{$\begin{array}{c}R \text {-square } \\
\text { change }\end{array}$} & \multicolumn{4}{|c|}{ Change statistics } & \multirow[t]{2}{*}{ Durbin-Watson } \\
\hline & & & & & & $F$ change & df1 & df2 & Sig. $F$ change & \\
\hline 1 & $0.118 \dagger$ & 0.014 & -0.001 & 0.25426 & 0.014 & 0.909 & 2 & 128 & 0.406 & 1.890 \\
\hline
\end{tabular}

Note: Model Summary, Dependent Variable: Nutrition_Knowl Belief.

$\dagger$, Predictors: (Constant), Reading_of_NInfor, Nutrition_LU5_7. 
TABLE 8: Multiple linear regression results - Coefficients.

\begin{tabular}{|c|c|c|c|c|c|c|c|c|c|c|c|c|}
\hline \multirow[t]{2}{*}{ Model 1} & \multicolumn{2}{|c|}{$\begin{array}{l}\text { Unstandardised } \\
\text { coefficients }\end{array}$} & \multirow{2}{*}{$\begin{array}{c}\text { Standardised } \\
\text { coefficients } \\
\text { Beta }\end{array}$} & \multirow[t]{2}{*}{$t$} & \multirow[t]{2}{*}{ Sig. } & \multicolumn{2}{|c|}{$\begin{array}{l}95.0 \% \text { confidence } \\
\text { interval for B }\end{array}$} & \multicolumn{3}{|c|}{ Correlations } & \multicolumn{2}{|c|}{ Collinearity statistics } \\
\hline & $B$ & Std. error & & & & Lower bound & Upper bound & Zero-order & Partial & Part & Tolerance & VIF \\
\hline (Constant) & 2.991 & 248 & - & 12.050 & 0.000 & 2.500 & 3.483 & - & - & - & - & - \\
\hline Nutrition_LU5_7 & 0.42 & 0.49 & 0.076 & 0.850 & 0.397 & -0.056 & 0.140 & 0.088 & 0.075 & 0.075 & 0.976 & 1.024 \\
\hline Reading_of_NInfor & 0.87 & 0.96 & 0.080 & 9.03 & 0.368 & -0.103 & 0.276 & 0.92 & 0.080 & 079 & 0.976 & 1.024 \\
\hline
\end{tabular}

Std. error, standard error; VIF, .

Note: Coefficients, Dependent variable: Nutrition_Knowl_Belief.

\section{Discussion}

The aim of this study was to measure the relationship between nutrition label use and nutrition knowledge. Three main findings of this study are reported in this section. Firstly, rural youth consumers' nutrition label use had no significant relationship with nutrition knowledge. Secondly, no significant difference existed by gender concerning nutrition knowledge. Finally, the level of education amongst the rural youth consumers studying at a university had no relationship with aspects of nutrition knowledge.

Generally, the study supports the notion that contextual issues appear to influence behaviours concerning nutrition knowledge (Kabir et al. 2018). Uniquely, the study illustrates this within a South African rural context. Furthermore, the study shows support of previous work that investigated the influence of demographic variables on nutrition label use (Psaltopoulou et al. 2017). It is encouraging, based on the finding, to note that gender has no influence on the relationship between nutrition label use and nutrition knowledge, albeit in South Africa where gender inequality exists. Of concern, however, is the finding that the level of education (measured by the number of years of tertiary education) did not relate to aspects of nutrition knowledge. Despite strides by countries, including South Africa, in publishing food-labelling legislation (Kempen et al. 2012), there appear to be challenges with regard to the influence of food labels on nutrition knowledge. Whatever the amount of educational progress, nutrition labels do not appear to be prioritised. This could be a familiarity that exists regarding this activity. Therefore, the issue is not so much about encouraging legislation that protects the consumer, as is the case globally (Ishak \& Zabil 2012), but changing attitudes of the intended beneficiary of such edicts, the consumer. Hence, efforts to change attitudes may improve decisions about reading nutrition labels (Miller et al. 2017) and inform on aspects of nutrition knowledge (Miller \& Cassady 2015).

\section{Recommendations}

Apart from advancing theory, marketers can benefit from the findings of this study. Marketers need to consider the factors that influence nutrition label use and nutrition knowledge amongst the youth as active consumers. This then can be a basis for encouraging interventions that not only promote responsible product use but also the health of the consumer. Based on the findings of the research, programmes can be encouraged to assist communities in better understanding the information on labels of products, given the link between nutrition label use and nutrition knowledge. It is envisaged that such a study and its implications can be a major means of encouraging consumers in making healthier choices.

\section{Limitations and future research}

The results of this study cannot be generalised to the entire population of youths that reside in rural communities or any other context. However, the results serve as a useful guideline for understanding issues concerning nutrition label use and nutrition knowledge. It is envisaged that this can be a useful precursor for interventions in improving sustainable livelihoods. Future research expanding on the findings of this quantitative study should be undertaken. For instance, such research could seek to explore further determinants of nutrition label use amongst youths against (1) the type of product, (2) frequency of use, (3) the role of the sociocultural milieu and even (4) culture. Future research should also take a qualitative stance in exploring the complexity that may accompany nutrition label use and reading and nutrition knowledge. Finally, consideration should be given to collecting data at multiple points, thus giving more robust data for understanding issues around nutrition label use and nutrition knowledge.

\section{Acknowledgements}

The financial assistance of the National Institute for the Humanities and Social Sciences (NIHSS) and the National Research Foundation (NRF) towards this research is greatly acknowledged. The authors are grateful to the University of Fort Hare (UFH) community for participating in the study.

\section{Competing interests}

The authors have declared that no competing interests exist.

\section{Authors' contributions}

N.X. was a post-doctoral fellow and was supervised by W.T.C. and H.S. The article was a joint effort between the authors.

\section{Funding information}

Financial assistance was provided by the National Institute for the Humanities and Social Sciences (NIHSS) and the National Research Foundation (NRF). 


\section{Data availability statement}

Data sharing is not applicable to this article as no new data were created or analysed in this study.

\section{Disclaimer}

Opinions expressed and conclusions arrived at in this article are those of the authors and are not necessarily to be attributed to the NIHSS and NRF.

\section{References}

Amy, M., 2019, 'Overview of youth at-risk behavior. Behavioral psychology', Verywellmind, viewed 03 March 2019, from https://www.verywellmind.com/ what-is-youth-at-risk-behavior-2610455.

Antwi, S.K. \& Hamza, K., 2015, 'Qualitative and quantitative research paradigms in business research: A philosophical reflection', European Journal of Business and Management 7(3), 217-225.

Azman, N. \& Sahak, S.Z., 2014, 'Nutritional label and consumer buying decision: A preliminary review', Procedia - Social and Behavioral Sciences 130, 490-498. https://doi.org/10.1016/j.sbspro.2014.04.057

Barreirro-Hurle, J., Gracia, A. \& De Magristis, T., 2010, 'Does nutrition information on food products lead to healthier food choices?', Food Policy 35, 221-229. https:// doi.org/10.1016/j.foodpol.2009.12.006

Coetzee, M., 2014, 'Measuring student graduateness: Reliability and construct validity of the graduate skills and attributes scale', Higher Education Research and Development 33(5), 887-902. https://doi.org/10.1080/07294360.2014.890572

De Magistris, T., Gracia, A. \& Barreiro-Hurle, J., 2010, 'Effects of the nutritional labels use on healthy eating habits in Spain', Agricultural Economics - Czech 56(11) 540-551. https://doi.org/10.17221/11/2010-AGRICECON

Deshmukh, N. \& Goyal, R., 2017, 'Food label reading knowledge and understanding among consumers', International Journal of Nutritional, Pharmacology Neurological Diseases 7(3), 71-72. https://doi.org/10.4103/ijnpnd.ijnpnd_11_17

Flynn, M.A.T., 2015, 'Empowering people to be healthier: Public health nutrition through the Ottawa Charter', Proceedings of the Nutrition Society 74(3), 303-312. https://doi.org/10.1017/S002966511400161X

Govender, K., Naicker, A., Napier, C.E. \& Singh, D., 2018, 'School snacking preferences of children from a low socio-economic status community in South Africa', Journal of Consumer Sciences 3, 1-10.

Govender, L., Pillay, K., Siwela, M., Modi, A. \& Mabhaudhi, T., 2017, 'Food and nutrition insecurity in selected rural communities of KwaZulu-Natal, South Africa - Linking human nutrition and agriculture', International Journal of Environmental Research and Public Health 14(1), 17. https://doi.org/10.3390/ijerph14010017

Grosso, G., Mistretta, A., Turconi, G., Cena, H., Roggi, C. \& Galvano, F., 2012, 'Nutrition knowledge and other determinants of food intake and lifestyle habits in children and young adolescents living in a rural area of Sicily, South Italy', Public Healt Nutrition 16(10), 1827-1836. https://doi.org/10.1017/\$1368980012003965

Grunert, K.G., Wills, J., Fernández Celemín, L., Lähteenmäki, L., Scholderer, J. \& Storcksdieck genannt Bonsmann, S., 2012, 'Socio-demographic and attitudinal determinants of nutrition knowledge of food shoppers in six European countries', Food Quality and Preference 26(3), 166-177. https://doi.org/10.1016/j.foodqual.2012.04.007

Guthrie, J., Mancino, L. \& Lin, C.J., 2015, 'Nudging consumers toward better food choices: Policy approaches to changing food consumption behaviors', Psychology and Marketing 32(5), 501-511. https://doi.org/10.1002/mar.20795

Hampshire, K., Porter, G., Owusu, S.A., Abane, S., Robson, A., Munthali, E. et al., 2015 'Informal m-health: How are young people using mobile phones to bridge
healthcare gaps in Sub-Saharan Africa?', Social Science \& Medicine 142, 90-99. healthcare gaps in Sub-Saharan Africa?, Social Scien
https://doi.org/10.1016/j.socscimed.2015.07.033

Hendriks, S.L. \& McIntyre, A., 2016, 'Why a diverse diet is crucial for rural South Africans', The Conversation, viewed 03 March 2019, from https://theconversation. Africans', The Conversation, viewed 03 March 2019, from https://the

IBM, 2016, IBM SPSS Statistics for Windows, Version 24.0, IBM Corp., Armonk, NY,

Ishak, S. \& Zabil, N.F.M., 2012, 'Impact of consumer awareness and knowledge to consumer effective behavior', Asian Social Science 8(13), 108-114. https://doi org/10.5539/ass.v8n13p108

Jones, N.R.V., Conklin, A.I., Suhrcke, M. \& Monsivais, P., 2014, 'The growing price gap between more and less healthy foods: Analysis of a novel longitudinal UK dataset', PLoS One 9(10), 1-7. https://doi.org/10.1371/journal.pone.0109343
Kabir, A., Miah, S. \& Islam, A., 2018, 'Factors influencing eating behavior and dietary intake among resident students in a public university in Bangladesh: A qualitative study', PLoS One 13(6), 1-17. https://doi.org/10.1371/journal.pone.0198801

Kempen, E.L., Muller, H., Symington, E. \& Van Eeden, T., 2012, 'A study of the relationship between health awareness, lifestyle behaviour and food label usage in Gauteng', South African Journal of Clinical Nutrition 25(1), 15-21. https://doi.or g/10.1080/16070658.2012.11734397

Kimani-Murage, E.W., Kahn, K., Pettifor, J.M., Tollman, S.M., Dunger, D.B., GómezOlivé, X.F. et al., 2010, 'The prevalence of stunting, overweight and obesity, and metabolic disease risk in rural South African children', BMC Public Health 10(158), 1-13. https://doi.org/10.1186/1471-2458-10-158

Koen, N., Blaauw, R. \& Wentzel-Viljoen, E., 2016, 'Food and nutrition labelling: The past, present and the way forward', South African Journal of Clinical Nutrition 29(1), 13-21. https://doi.org/10.1080/16070658.2016.1215876

Krause, C.G., Beer-Borst, S., Sommerhalder, K., Hayoz, S. \& Abel, T., 2018, 'A short food literacy questionnaire (SFLQ) for Adults: Findings from a Swiss validation study', Appetite 120, 275-280. https://doi.org/10.1016/j.appet.2017.08.039

Laz, T.H., Rahman, M., Pohlmeier, A.M. \& Berenson, A.B., 2015, 'Level of nutrition knowledge and its association with weight loss behaviors among low-income reproductive-age women', Journal of Community Health 40(3), 542-548. https:// doi.org/10.1007/s10900-014-9969-9

Matthews, J.I., Doerr, L. \& Dworatzek, P.D.N., 2016, 'University students intend to eat better but lack coping self-efficacy and knowledge of dietary recommendations', Journal of Nutrition Education and Behavior 48(1), 12-19. https://doi. org/10.1016/j.jneb.2015.08.005

Miller, L.M.S., Beckett, L.A., Bergman, J.J., Wilson, M.D., Applegate, E.A. \& Gibson, T.N., 2017, 'Developing nutrition label reading skills: A web-based practice approach', Journal of Medical Internet Research 19(1), 1-12.

Miller, L.M.S. \& Cassady, D.L., 2015, 'The effects of nutrition knowledge on food label use. A review of the literature', Appetite 92, 207-216. https://doi.org/10.2196/jmir.6583

Miller, L.M., Cassady, D.L., Beckett, L.A., Applegate, E.A., Wilson, M.D., Gibson, T.N. et al., 2015, 'Misunderstanding of front-of-package nutrition information on US food products', PLoS One 10(4), 1-11. https://doi.org/10.1371/journal.pone.0125306

Moore, S.G., Donelly, J.K., Jones, S. \& Cade, J.E., 2018, 'Effect of educational interventions on understanding and use of nutrition labels: A systematic review', Nutrients 10(10), 1-14. https://doi.org/10.3390/nu10101432

Nunnally, J.C., 1978, Psychometric theory, 2nd edn., McGraw-Hill, New York.

Page, J., 2012, Youth, jobs and structural change: Confronting Africa's employment problem, African Development Bank, Tunisia.

Parliamentary Monitoring Group, 2016, Water challenges: Hearings with municipalities, viewed 24 May 2019, from www.pmg.org.za.

Pechey, R. \& Monsivais, P., 2016, 'Socio-economic inequalities in the healthiness of food choices: Exploring the contributions of food expenditures', Preventive Medicine 88, 203-206. https://doi.org/10.1016/j.ypmed.2016.04.012

Petrovici, D., Fearne, A., Nayga, R.M., Jr. \& Drolias, D., 2012, 'Nutritional knowledge, nutritional labels, and health claims on food: A study of supermarket shoppers in the South East of England', British Food Journal 114(6), 768-783. https://doi. org/10.1108/00070701211234318

Picincu, A., 2018, 'The advantages of using a questionnaire', Bizfluent, viewed from https://bizfluent.com/info-8206848-advantages-using-questionnaire.html.

Pretorius, S. \& Sliwa, K., 2011, 'Perspectives and perceptions on the consumption of a healthy diet in Soweto, an urban African community in South Africa', SA Heart Winter 8(3), 178-183. https://doi.org/10.24170/8-3-1897

Psaltopoulou, T., Hatzis, G., Papageorgiou, N., Androulakis, E., Briasoulis, A. \& Tousoulis, D., 2017, 'Socio-economic status and risk factors for cardiovascular disease: Impact of dietary mediators. A review', Hellenic Society of Cardiology 58(1), 32-42. https://doi.org/10.1016/j.hjc.2017.01.022

Romanos-Nanclares, A., Zazpe, I., Santiago, S., Marín, L., Rico-Campà, A. \& Martín-Calvo, N., 2018, 'Influence of parental healthy-eating attitudes and nutritional knowledge on nutritional adequacy and diet quality among pre-schoolers: The SENDO project' Nutrients 10(12), 1-14. https://doi.org/10.3390/nu10121875

SPSS, 2018, SPSS Statistics for Windows, Version 24.0, SPSS Inc., Chicago, IL.

Van der Merwe, D., Bosman, M., Ellis, S., De Beer, H. \& Mielmann, A., 2013 'Consumers' knowledge of food label information: An exploratory investigation in Potchefstroom, South Africa', Public Health Nutrition 16(3), 403-408. https://doi. org/10.1017/S136898001200287X

Van Schalkwyk, B.B., 2015, 'Challenges in realising sustainable community development in rural South Africa. Agriculture, Forestry and Fisheries', Rural Areas 4(4-1), 73-79. https://doi.org/10.11648/j.aff.s.2015040401.19

World Health Organization, 2014, World Health Organization (WHO) poverty, World Health Organization, Geneva. 